\title{
Plastic Design Theory of Frozen Wall Thickness in an Ultradeep Soil Layer Considering Large Deformation Characteristics
}

\author{
Bo Zhang, Weihao Yang (iD, and Baosheng Wang \\ State Key Laboratory for Geomechanics and Deep Underground Engineering, China University of Mining and Technology, \\ Xuzhou 221116, China \\ Correspondence should be addressed to Weihao Yang; whyang@cumt.edu.cn
}

Received 23 December 2017; Revised 12 April 2018; Accepted 30 April 2018; Published 31 May 2018

Academic Editor: Francesco Marotti de Sciarra

Copyright (C) 2018 Bo Zhang et al. This is an open access article distributed under the Creative Commons Attribution License, which permits unrestricted use, distribution, and reproduction in any medium, provided the original work is properly cited.

Frozen wall design theory is a key technique of the freezing method. However, previous design theories for a deep artificial frozen wall have neglected the influence of shaft flank displacement, that is, the displacement of the inner boundary of a frozen wall. Thus, the associated designs tend to be unsafe and earthwork excavations tend to be underestimated. This study builds a new design theory for frozen wall thickness which considers the influence of a large strain and obtains new solution formulas for the thickness and excavation radius before deformation occurs. The analytical results are compared with numerical calculation results by analyzing the influences of various parameters, such as crustal stress, cohesion and internal friction angle of frozen soil, and cohesion and internal friction angle of unfrozen soil as well as the elastic modulus of the ground, on the frozen wall thickness and the shaft flank displacement. The results indicate that the new formula is applicable for large deformation calculation with a strain of up to 0.2 . The new formula can accurately calculate the amount of excavation earthwork and serves as a safer and more reasonable theoretical support for the design of frozen walls in ultradeep soil layers.

\section{Introduction}

The freezing method is the primary sinking method used in deep and unstable aquifer strata, and it is used in more than $90 \%$ of shaft sinking projects. The freezing method is a special shaft sinking method in which deep holes surrounding the shaft are drilled before excavation, the freezing pipes are placed into holes, and then low temperature brine is circulated in freezing pipes to freeze the ground into an enclosed curtain (frozen wall) to resist ground pressure and water seepage; finally, the well is dug and a shaft lining is built under the protection of the frozen wall $[1,2]$.

The German engineer Poetsch invented the freezing method in 1883, and since then the method has been used worldwide and represents an effective method of building wells in complex formations. Implementation of the freezing method in the former Soviet Union, Poland, Germany, and other countries outside of China includes eight frozen shafts that passed through soil thicknesses of more than $400 \mathrm{~m}$, with four exceeding a depth of $500 \mathrm{~m}$ through alluvium and the maximum depth reaching $571 \mathrm{~m}$ [3]. In China, approximately 1100 frozen shafts were constructed from 1956 to 2018. After 2002, the number of frozen shafts with soil depth that exceeded $400 \mathrm{~m}, 500 \mathrm{~m}, 600 \mathrm{~m}$, and $700 \mathrm{~m}$ was $71,28,4$, and 3 , respectively. The deepest shaft extended to $753.95 \mathrm{~m}$, which represents the world record for shaft topsoil thickness.

Freezing shaft sinking increases in difficulty as the soil thickness increases, and one of the key techniques for addressing this problem is frozen wall design theory. In general, the mechanical model of thick-walled cylinder is adopted for designing the frozen wall thickness. Practice shows that the G. Lame formula is ideal for calculating the frozen wall thickness for a soil depth of approximately $150 \mathrm{~m}$ and the O. Domke formula is applicable for the soil depth of approximately $300 \mathrm{~m}$, and when the alluvium depth reaches the range of $300 \mathrm{~m}$ to $400 \mathrm{~m}$, the Liberman and Vialov formulas are appropriate for designing the frozen wall thickness. Yang et al. [4, 5] assumed that the frozen wall is an ideal homogenous elastoplastic and plastic material, respectively, which follows the Mohr-Coulomb yield criterion, and based on a planar strain and asymmetrical 
unloading model, they deduced a strict analytical solution that considers the interaction between the frozen wall and the surrounding soil as well as the effect of initial stress field. Consequently, the formulas for calculating the frozen wall thickness were obtained and successfully applied in the design of frozen walls at soil depths of 400 to $800 \mathrm{~m}$. Field measurements illustrate that the radial absolute displacement of the frozen wall in the vertical shaft at soil depths of $500 \sim 800 \mathrm{~m}$ can exceed $10 \%$ of the excavation radius $[6,7]$, although the average temperature can reach $-15 \sim-25^{\circ} \mathrm{C}$. When the soil depth reaches up to $800 \sim 1000 \mathrm{~m}$, the radial absolute displacement will be significantly greater, and it exhibits the obviously large deformation characteristics of the frozen wall.

Under large deformation conditions, the size and location of the frozen wall are significantly different before and after the deformation; however, these parameters are neglected in previous small deformation formulas, which will result in great error to the design for frozen wall thickness in ultradeep soil layers. Due to the fact that the design of a frozen wall thickness is similar to a cavity contraction (expansion), the analytical solutions of a cavity contraction (expansion), including perfect plasticity, strain hardening, and softening [8-18], are of great importance for designing a frozen wall thickness. The problems of both cylindrical cavities contraction (externally pressurized) and expansion (internally pressurized) in an infinite isotropic medium using the Mohr-Coulomb and the Drucker-Prager hardening solids were reported by Papanastasiou and Durban [19-21], while the derived differential equations had to be solved numerically.

As finding an analytical solution for the large deformation mechanical problems is very difficult, in this paper, the authors take reference of the elastoplastic large-strain solutions proposed by Papanastasiou and Durban [19-21] and comprehensively consider the in situ stress, the unloading condition, and the interaction between frozen soil and surrounding soil, as well as using some reasonable assumptions to simplify the large-strain solutions, and then we present a new calculation formula for frozen wall thickness which is applicable to a certain range of large deformation. The work provides a theoretical basis for frozen wall design in an ultradeep soil layer.

\section{Mechanical Model}

2.1. Basic Assumptions. (1) The frozen wall and unfrozen soil exhibit an axisymmetric distribution and are in the planar strain state.

(2) The frozen wall is an ideal homogeneous plastic material, and the volume is incompressible in the plastic zone. Unfrozen soil is a homogenous elastic material whose elastic modulus and Poisson's ratio are $E_{\mathrm{u}}$ and $\mu_{\mathrm{u}}$, respectively.

(3) The excavation is finished in a single instant within the radius $r_{1}$.

(4) The initial in situ stress is constant before and after freezing, and the initialdisplacement is zero.

2.2. Definite Solution Conditions. The mechanical model is divided into two parts (see Figure 1): (1) the frozen wall zone

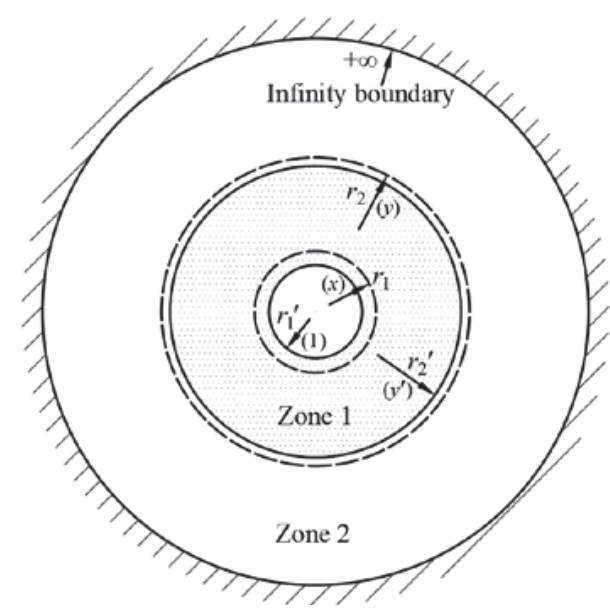

Figure 1: Mechanical model.

(zone 1) with radial stress $\sigma_{1 r}$, circumferential stress $\sigma_{1 \theta}$, and displacement $u_{1 r}$; (2) the unfrozen ground zone (zone 2) with related parameters indicated by $\sigma_{2 r}, \sigma_{2 \theta}$, and $u_{2 r}$, respectively. Moreover, $r_{1}$ and $r_{2}$ are the interior and external radii of the frozen wall before deformation, respectively. $r_{1}^{\prime}$ and $r_{2}^{\prime}$ are the interior and external radii of the frozen wall after deformation, respectively. The horizontal ground pressure is $p_{0}$. The dimensionless radial and circumferential stresses are $\bar{\sigma}_{i r}=\sigma_{i r} / p_{0}$ and $\bar{\sigma}_{i \theta}=\sigma_{i \theta} / p_{0}(i=1,2$, presenting zone 1 and zone 2 , resp.), the dimensionless displacement is $\bar{u}_{i r}=$ $u_{i r} / r_{1}^{\prime}$, the dimensionless radial coordinates are $\xi=r / r_{1}^{\prime}$ and $\xi^{\prime}=r^{\prime} / r_{1}^{\prime}$, and the dimensionless inner and outer radii before deformation are $x=r_{1} / r_{1}^{\prime}$ and $y=r_{2} / r_{1}^{\prime}$ respectively. After deformation, the dimensionless internal and external radii are 1 and $y^{\prime}=r_{2}^{\prime} / r_{1}^{\prime}$. The initial stresses of the aforementioned zones prior to excavation are expressed as

$$
\bar{\sigma}_{r}^{0}=\bar{\sigma}_{\theta}^{0}=-1,
$$

where $\bar{\sigma}_{r}^{0}=\sigma_{r}^{0} / p_{0}, \bar{\sigma}_{\theta}^{0}=\sigma_{\theta}^{0} / p_{0}$, and $\sigma_{r}^{0}$ and $\sigma_{\theta}^{0}$ are radial and hoop initial ground stress.

After excavation, the stress boundary condition at excavation radius $\xi=x$ is

$$
\left.\bar{\sigma}_{1 r}\right|_{\xi=x}=0 .
$$

At $\xi \rightarrow+\infty$, the displacement and stress boundary condition are

$$
\begin{aligned}
& \left.\bar{u}_{2 r}\right|_{\xi \rightarrow+\infty}=0, \\
& \left.\bar{\sigma}_{2 r}\right|_{\xi \rightarrow+\infty}=\left.\bar{\sigma}_{2 \theta}\right|_{\xi \rightarrow+\infty}=-1 .
\end{aligned}
$$

At $\xi=y$, the radial stress and displacement continuous conditions are

$$
\begin{aligned}
& \left.\bar{\sigma}_{1 r}\right|_{\xi=y}=\left.\bar{\sigma}_{2 r}\right|_{\xi=y}, \\
& \left.\bar{u}_{1 r}\right|_{\xi=y}=\left.\bar{u}_{2 r}\right|_{\xi=y} .
\end{aligned}
$$




\section{Stress and Displacement Solutions}

3.1. Stress and Displacement Solutions for the Frozen Wall. The dimensionless equilibrium equation of the frozen wall is

$$
\frac{\mathrm{d} \bar{\sigma}_{1 r}}{\mathrm{~d} \xi}+\frac{\bar{\sigma}_{1 r}-\bar{\sigma}_{1 \theta}}{\xi}=0 .
$$
[22]:

The frozen soil follows the Mohr-Coulomb yield criterion

$$
a_{\mathrm{f}} \bar{\sigma}_{1 r}-\bar{\sigma}_{1 \theta}=b_{\mathrm{f}}
$$

where $a_{\mathrm{f}}=\left(1+\sin \varphi_{\mathrm{f}}\right) /\left(1-\sin \varphi_{\mathrm{f}}\right), b_{\mathrm{f}}=\left(2 \bar{c}_{\mathrm{f}} \cos \varphi_{\mathrm{f}}\right) /(1-$ $\left.\sin \varphi_{\mathrm{f}}\right), \bar{c}_{\mathrm{f}}=c_{\mathrm{f}} / p_{0}$, and $c_{\mathrm{f}}$ and $\varphi_{\mathrm{f}}$ are the cohesion and internal friction angle of frozen soil, respectively.

Substituting (8) into (7) and combining boundary condition (2), the radial stress solution of the frozen wall is obtained as

$$
\bar{\sigma}_{1 r}=-\frac{b_{\mathrm{f}}}{a_{\mathrm{f}}-1}\left[\left(\frac{\xi}{x}\right)^{a_{\mathrm{f}}-1}-1\right] .
$$

Substituting (9) into (8), circumferential stress is obtained as

$$
\bar{\sigma}_{1 \theta}=-\frac{a_{\mathrm{f}} b_{\mathrm{f}}}{a_{\mathrm{f}}-1}\left[\left(\frac{\xi}{x}\right)^{a_{\mathrm{f}}-1}-1\right]-b_{\mathrm{f}} .
$$

The strain of frozen wall is the sum of elastic strain and plastic strain, which is

$$
\begin{aligned}
& \varepsilon_{1 r}=\varepsilon_{1 r}^{\mathrm{e}}+\varepsilon_{1 r}^{\mathrm{p}} \\
& \varepsilon_{1 \theta}=\varepsilon_{1 \theta}^{\mathrm{e}}+\varepsilon_{1 \theta}^{\mathrm{p}},
\end{aligned}
$$

where $\varepsilon_{1 r}$ and $\varepsilon_{1 \theta}$ are radial and circumferential strain, $\varepsilon_{1 r}^{\mathrm{e}}$ and $\varepsilon_{1 \theta}^{\mathrm{e}}$ are radial and circumferential elastic strain, and $\varepsilon_{1 r}^{\mathrm{p}}$ and $\varepsilon_{1 \theta}^{\mathrm{p}}$ are radial and circumferential plastic strain.

Elastoplastic constitutive relations $[22,23]$ are described as

$$
\begin{aligned}
& \varepsilon_{1 r}^{\mathrm{e}}=\frac{\left(1-\mu_{\mathrm{f}}\right)\left(\bar{\sigma}_{1 r}-\bar{\sigma}_{r}^{0}\right)-\mu_{\mathrm{f}}\left(\bar{\sigma}_{1 \theta}-\bar{\sigma}_{\theta}^{0}\right)}{2 \bar{G}_{\mathrm{f}}} \\
& \varepsilon_{1 \theta}^{\mathrm{e}}=\frac{\left(1-\mu_{\mathrm{f}}\right)\left(\bar{\sigma}_{1 \theta}-\bar{\sigma}_{\theta}^{0}\right)-\mu_{\mathrm{f}}\left(\bar{\sigma}_{1 r}-\bar{\sigma}_{r}^{0}\right)}{2 \bar{G}_{\mathrm{f}}},
\end{aligned}
$$

where $\bar{G}_{\mathrm{f}}=\bar{E}_{\mathrm{f}} / 2\left(1+\mu_{\mathrm{f}}\right)$ and $\bar{E}_{\mathrm{f}}=E_{\mathrm{f}} / p_{0}$. The elastic modulus and Poisson's ratio of frozen soil are $E_{\mathrm{f}}$ and $\mu_{\mathrm{f}}$, respectively. Substituting (1) into (12),

$$
\begin{aligned}
& \varepsilon_{1 r}^{\mathrm{e}}=\frac{\left(1-\mu_{\mathrm{f}}\right)\left(\bar{\sigma}_{1 r}+1\right)-\mu_{\mathrm{f}}\left(\bar{\sigma}_{1 \theta}+1\right)}{2 \bar{G}_{\mathrm{f}}} \\
& \varepsilon_{1 \theta}^{\mathrm{e}}=\frac{\left(1-\mu_{\mathrm{f}}\right)\left(\bar{\sigma}_{1 \theta}+1\right)-\mu_{\mathrm{f}}\left(\bar{\sigma}_{1 r}+1\right)}{2 \bar{G}_{\mathrm{f}}} .
\end{aligned}
$$

The expression of Mohr-Coulomb plastic potential function can be expressed as [21]

$$
\bar{\phi}=\beta_{\mathrm{f}} \bar{\sigma}_{1 r}-\bar{\sigma}_{1 \theta}
$$

where $\bar{\phi}=\phi / p_{0}, \beta_{\mathrm{f}}=\left(1+\sin \psi_{\mathrm{f}}\right) /\left(1-\sin \psi_{\mathrm{f}}\right), \phi$ is the plastic potential function, and $\psi_{\mathrm{f}}$ is the dilatancy angle of frozen soil. According to the literature [23], the plastic potential is identical to the yield condition when the internal friction angle $\varphi_{\mathrm{f}}$ is equal to the dilatancy angle $\psi_{\mathrm{f}}$, and the associated Mohr-Coulomb flow rule is obtained. Moreover, nonassociativity is defined by deviation from associativity through decreasing of $\psi_{\mathrm{f}}$, which can be expressed as $0 \leq$ $\psi_{\mathrm{f}}<\varphi_{\mathrm{f}}$. In view of a weaker material behavior induced by nonassociativity [23], the nonassociated flow rule should be applied when the frozen wall attains the plastic state.

Based on the plastic potential theory, the expressions of plastic strain are [20]

$$
\begin{aligned}
& \varepsilon_{1 r}^{\mathrm{p}}=\lambda \frac{\partial \bar{\phi}}{\partial \bar{\sigma}_{1 r}}=\lambda \beta_{\mathrm{f}} \\
& \varepsilon_{1 \theta}^{\mathrm{p}}=\lambda \frac{\partial \bar{\phi}}{\partial \bar{\sigma}_{1 \theta}}=-\lambda,
\end{aligned}
$$

where $\lambda$ is the plastic scale coefficient.

From (15), the relationship of the plastic strains is obtained:

$$
\varepsilon_{1 r}^{\mathrm{p}}+\beta_{\mathrm{f}} \varepsilon_{1 \theta}^{\mathrm{p}}=0
$$

Substituting (11) into (16), the expression is got by

$$
\varepsilon_{1 r}+\beta_{\mathrm{f}} \varepsilon_{1 \theta}=\varepsilon_{1 r}^{\mathrm{e}}+\beta_{\mathrm{f}} \varepsilon_{1 \theta}^{\mathrm{e}} .
$$

In order to consider the effect of large strain on plastic zone, the logarithmic strains [24] should be used, and the geometric equations are

$$
\begin{aligned}
& \varepsilon_{r}=\ln \left(\frac{\mathrm{d} \xi^{\prime}}{\mathrm{d} \xi}\right), \\
& \varepsilon_{\theta}=\ln \left(\frac{\xi^{\prime}}{\xi}\right), \\
& \varepsilon_{z}=0
\end{aligned}
$$

where $\xi$ and $\xi^{\prime}$ are the dimensionless coordinates before and after deformation, respectively.

Substituting (18) into (17), we got

$$
\ln \left[\frac{\mathrm{d} \xi^{\prime}}{\mathrm{d} \xi}\left(\frac{\xi^{\prime}}{\xi}\right)^{\beta_{\mathrm{f}}}\right]=\varepsilon_{1 r}^{\mathrm{e}}+\beta_{\mathrm{f}} \varepsilon_{1 \theta}^{\mathrm{e}} .
$$

Taking (9) and (10) into (13),

$$
\begin{aligned}
& \varepsilon_{1 r}^{\mathrm{e}}=A_{1}\left(\frac{\xi}{x}\right)^{a_{\mathrm{f}}-1}+A_{3} \\
& \varepsilon_{1 \theta}^{\mathrm{e}}=A_{2}\left(\frac{\xi}{x}\right)^{a_{\mathrm{f}}-1}+A_{3},
\end{aligned}
$$

where $A_{1}=\left[\mu_{\mathrm{f}}\left(a_{\mathrm{f}}+1\right)-1\right] b_{\mathrm{f}} / 2 \bar{G}_{\mathrm{f}}\left(a_{\mathrm{f}}-1\right), A_{2}=\left[\mu_{\mathrm{f}}\left(a_{\mathrm{f}}+1\right)-\right.$ $\left.a_{\mathrm{f}}\right] b_{\mathrm{f}} / 2 \bar{G}_{\mathrm{f}}\left(a_{\mathrm{f}}-1\right)$, and $A_{3}=\left(\left(1-2 \mu_{\mathrm{f}}\right) / 2 \bar{G}_{\mathrm{f}}\right)\left(\left(a_{\mathrm{f}}+b_{\mathrm{f}}-1\right) /\left(a_{\mathrm{f}}-1\right)\right)$. 


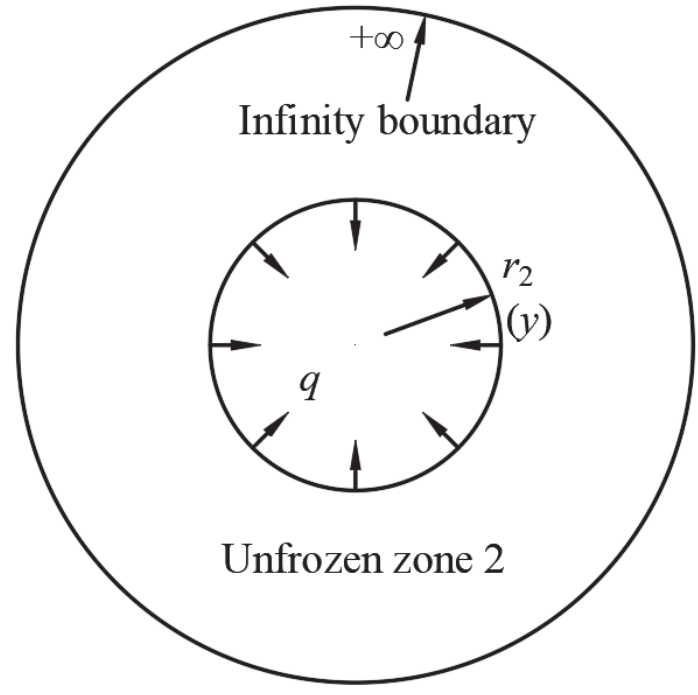

FIGURE 2: Unloading model.

Substituting (20) into (19),

$$
\ln \left[\frac{\mathrm{d} \xi^{\prime}}{\mathrm{d} \xi}\left(\frac{\xi^{\prime}}{\xi}\right)^{\beta_{\mathrm{f}}}\right]=A_{4}\left(\frac{\xi}{x}\right)^{a_{\mathrm{f}}-1}+A_{5}
$$

where $A_{4}=A_{1}+\beta_{\mathrm{f}} A_{2}$ and $A_{5}=\left(\beta_{\mathrm{f}}+1\right) A_{3}$. The solution for (21) is

$$
\left(\xi^{\prime}\right)^{\beta_{\mathrm{f}}+1}-1=\left(\beta_{\mathrm{f}}+1\right) \int_{x}^{\xi} \xi^{\beta_{\mathrm{f}}} e^{A_{4}(\xi / x)^{a_{\mathrm{f}}-1}+A_{5}} \mathrm{~d} \xi .
$$

The whole frozen wall attains the plastic state; then, substituting the outer radii of a frozen wall before and after deformation into (22),

$$
\left(y^{\prime}\right)^{\beta_{\mathrm{f}}+1}-1=\left(\beta_{\mathrm{f}}+1\right) \int_{x}^{y} \xi^{\beta_{\mathrm{f}}} e^{A_{4}(\xi / x)^{a_{\mathrm{f}}-1}+A_{5}} \mathrm{~d} \xi
$$

3.2. Stress and Displacement Solutions for Unfrozen Soil Zone. The solutions of the stress and displacement for the unfrozen zone are equal to the superposition of the unloading model solution [25] (Figure 2) and the initial ground stress and displacement. Therefore, according to the thick-walled-cylinder equation [26] and considering the interaction between the frozen wall and the surrounding soil, the stress and displacement solutions for the unfrozen zone can be determined in combination with (3) and (4):

$$
\begin{aligned}
& \bar{\sigma}_{2 r}=-1+q \frac{y^{2}}{\xi^{2}} \\
& \bar{\sigma}_{2 \theta}=-1-q \frac{y^{2}}{\xi^{2}}, \\
& \bar{u}_{2 r}=-\frac{q}{2 \bar{G}_{\mathrm{u}}} \frac{y^{2}}{\xi},
\end{aligned}
$$

where $\bar{G}_{\mathrm{u}}=\bar{E}_{\mathrm{u}} / 2\left(1+\mu_{\mathrm{u}}\right), \bar{E}_{\mathrm{u}}=E_{\mathrm{u}} / p_{0}$, and $q$ is a dimensionless load.
The inner-edge stresses of unfrozen zone can be obtained from (24):

$$
\begin{aligned}
& \left.\bar{\sigma}_{2 r}\right|_{\xi=y}=-1+q \\
& \left.\bar{\sigma}_{2 \theta}\right|_{\xi=y}=-1-q .
\end{aligned}
$$

According to the assumptions and definite solution conditions in Section 2, it is necessary to ensure that the surrounding soil does not attain the plastic state. At most, (26) satisfies the $\mathrm{M}-\mathrm{C}$ yield criterion,

$$
\left.a_{\mathrm{u}} \bar{\sigma}_{2 r}\right|_{\xi=y}-\left.\bar{\sigma}_{2 \theta}\right|_{\xi=y}=b_{\mathrm{u}}
$$

where $a_{\mathrm{u}}=\left(1+\sin \varphi_{\mathrm{u}}\right) /\left(1-\sin \varphi_{\mathrm{u}}\right), b_{\mathrm{u}}=\left(2 \bar{c}_{\mathrm{u}} \cos \varphi_{\mathrm{u}}\right) /(1-$ $\left.\sin \varphi_{\mathrm{u}}\right), \bar{c}_{\mathrm{u}}=c_{\mathrm{u}} / p_{0}$, and $c_{\mathrm{u}}$ and $\varphi_{\mathrm{u}}$ are the cohesion and internal friction angle of unfrozen soil, respectively.

Taking (26) into (27), one has

$$
q=\frac{a_{\mathrm{u}}+b_{\mathrm{u}}-1}{a_{\mathrm{u}}+1} .
$$

The outer-edge radial stress of the frozen wall is obtained by (9):

$$
\left.\bar{\sigma}_{1 r}\right|_{\xi=y}=-\frac{b_{\mathrm{f}}}{a_{\mathrm{f}}-1}\left[\left(\frac{y}{x}\right)^{a_{\mathrm{f}}-1}-1\right] .
$$

Substituting (29) and the first equation of (26) into (5), the expression of $q$ also can be expressed as

$$
q=1-\frac{b_{\mathrm{f}}}{a_{\mathrm{f}}-1}\left[\left(\frac{y}{x}\right)^{a_{\mathrm{f}}-1}-1\right] .
$$

Combining (28) with (30), the relationship of inner and outer radii can be got by

$$
\frac{y}{x}=\left[1+\frac{\left(a_{\mathrm{f}}-1\right)\left(2-b_{\mathrm{u}}\right)}{b_{\mathrm{f}}\left(a_{\mathrm{u}}+1\right)}\right]^{1 /\left(a_{\mathrm{f}}-1\right)} .
$$

\section{New Calculation Equation for the Frozen Wall Thickness}

4.1. Derivation of the New Calculation Equation. The locations prior to and after excavation deformation are shown in Figure 3. The internal radius, external radius, and thickness of frozen wall are changed from $r_{1}$ to $r_{1}^{\prime}$, from $r_{2}$ to $r_{2}^{\prime}$, and from $T$ to $T^{\prime}$.

If the effect of deformation on the size and location of frozen wall is not considered, the design of frozen wall thickness can meet the safety requirements according to the size after deformation; namely,

$$
\begin{aligned}
& x=1 \\
& y=y^{\prime} .
\end{aligned}
$$

Substituting (32) into (31), the outer-edge size of the frozen wall after deformation is obtained as

$$
y^{\prime}=\left[1+\frac{\left(a_{\mathrm{f}}-1\right)\left(2-b_{\mathrm{u}}\right)}{b_{\mathrm{f}}\left(a_{\mathrm{u}}+1\right)}\right]^{1 /\left(a_{\mathrm{f}}-1\right)} .
$$




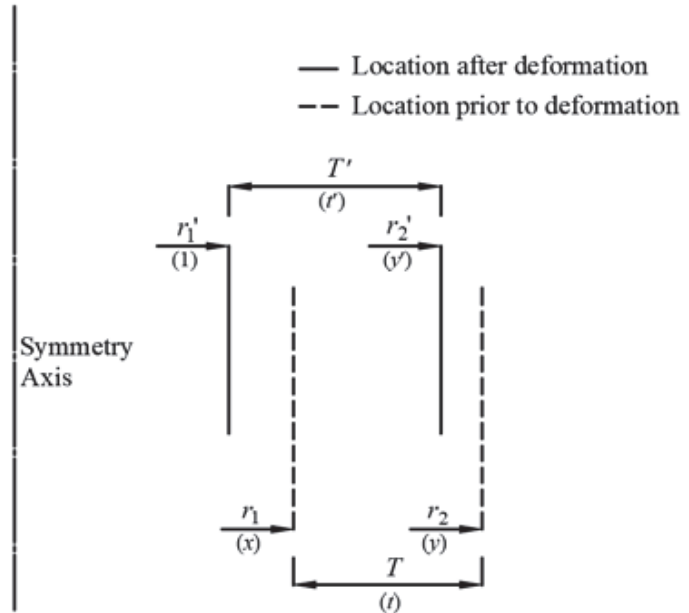

FIgURE 3: The locations prior to and after deformation.

Equation (33) is the same as Yang's plastic formula [5]. If $a_{\mathrm{f}}=1$ and $a_{\mathrm{u}}=1, b_{\mathrm{u}}=0$; then (33) degenerates into

$$
y^{\prime}=e^{1 / b_{\mathrm{f}}},
$$

and (34) is the same as the formula of Liberman [27].

The dimensionless thickness of the frozen wall after deformation is

$$
t^{\prime}=\frac{T^{\prime}}{r_{1}^{\prime}}=y^{\prime}-1
$$

After shaft excavation, the displacements at the internal and external edges of frozen wall (considering the large deformation characteristics) are provided by

$$
\begin{aligned}
& \left.\bar{u}_{1 r}\right|_{\xi=x}=1-x, \\
& \left.\bar{u}_{1 r}\right|_{\xi=y}=\left.\bar{u}_{2 r}\right|_{\xi=y}=y^{\prime}-y .
\end{aligned}
$$

From (25),

$$
\left.\bar{u}_{2 r}\right|_{\xi=y}=-\frac{q y}{2 \bar{G}_{\mathrm{u}}} .
$$

Combining (23) and (33) with (36) (38), the iterative formulas for the internal and external radii of frozen wall before deformation are determined as follows:

$$
\begin{aligned}
\left(y^{\prime}\right)^{\beta_{\mathrm{f}}+1}-1 & =\left(\beta_{\mathrm{f}}+1\right) \int_{x}^{y} \xi^{\beta_{\mathrm{f}}} e^{A_{4}(\xi / x)^{a_{\mathrm{f}}-1}+A_{5}} \mathrm{~d} \xi \\
y & =\frac{y^{\prime}}{1-q / 2 \bar{G}_{\mathrm{u}}} .
\end{aligned}
$$

Equation (39) can only be solved by numerical method.

According to the hypothesis that the volume of plastic zone is incompressible $\left(\mu_{\mathrm{f}}=0.5\right.$ and $\left.\psi_{\mathrm{f}}=0\right)$, the elastic

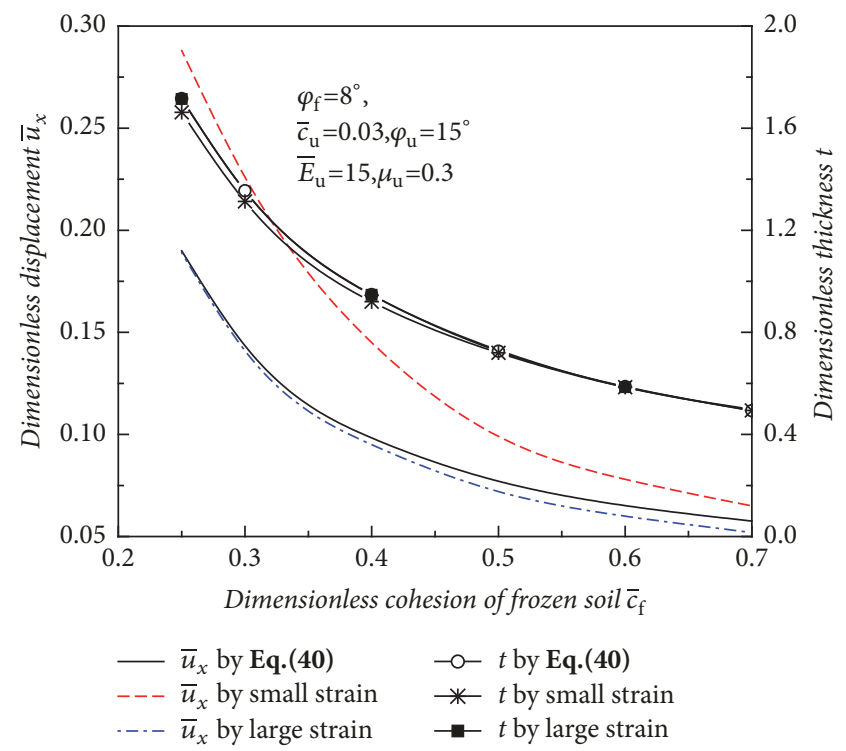

Figure 4: Influence of $\bar{c}_{\mathrm{f}}$ on $\bar{u}_{x}$ and $t$.

deformation of plastic zone is neglected [6, 7]; (39) is simplified as

$$
\begin{aligned}
& x=\sqrt{1+y^{2}-\left(y^{\prime}\right)^{2}} \\
& y=\frac{y^{\prime}}{1-q / 2 \bar{G}_{\mathrm{u}}} .
\end{aligned}
$$

Apparently, the frozen wall discussed here, for $\mu_{\mathrm{f}}=0.5$ and $\psi_{\mathrm{f}}=0$, is a fully incompressible solid, which is extremely nonassociated.

The dimensionless thickness of the frozen wall before deformation is

$$
t=y-x
$$

The dimensionless side-wall displacement of a shaft is

$$
\bar{u}_{x}=x-1 \text {. }
$$

Comparing the situations of neglecting and considering side-wall displacement, the underestimated percentage of excavation volume is obtained as follows:

$$
w_{1}=100\left(x^{2}-1\right) .
$$

4.2. Comparisons and Calibrations. Given typical engineering parameters, the finite-element model of unit depth [28$30]$ is established by the size of the frozen wall by formula (33). The calculation results obtained by the new formula (40) are compared to those obtained from the finite-element calculations based on small and large deformation theory. The comparisons of the results are presented in Figures 4-8. The elastic modulus and Poisson's ratio of frozen soil in numerical calculation are $\bar{E}_{\mathrm{f}}=E_{\mathrm{f}} / p_{0}=60$ and $\mu_{\mathrm{f}}=0.2$; horizontal ground pressure $p_{0}=1$. 


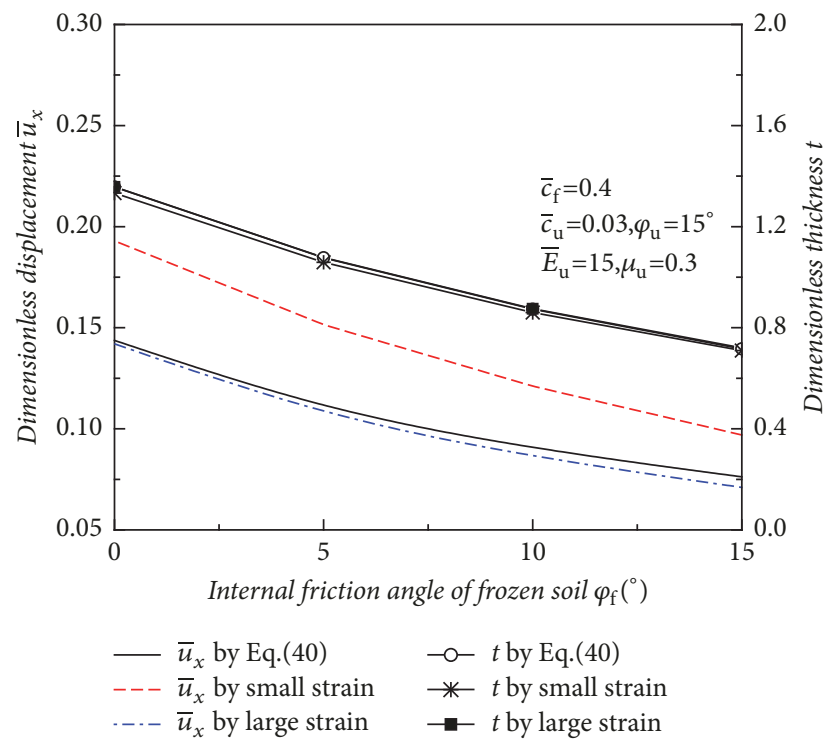

Figure 5: Influence of $\varphi_{\mathrm{f}}$ on $\bar{u}_{x}$ and $t$.

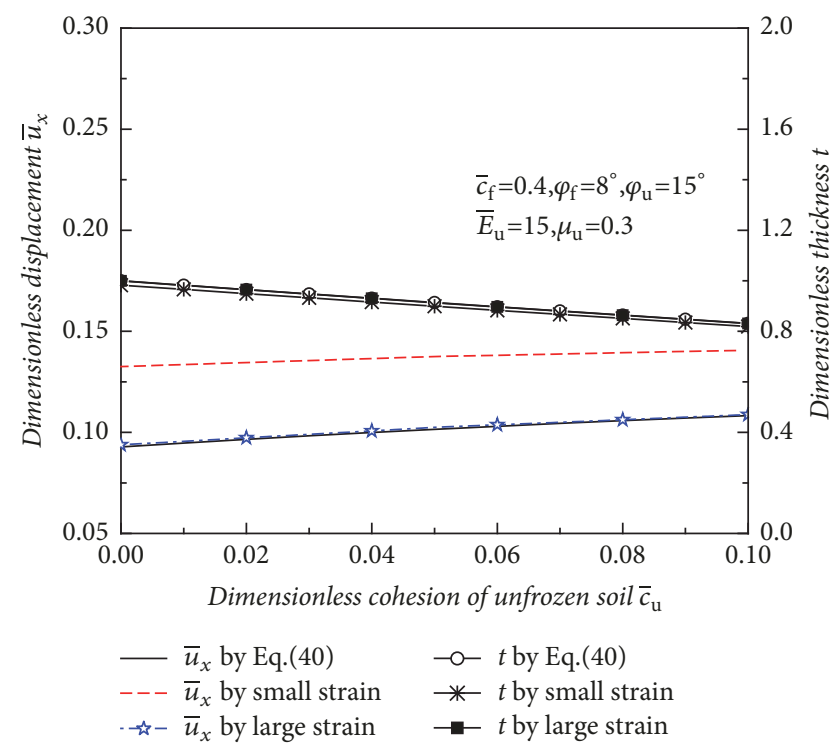

FIgURE 6: Influence of $\bar{c}_{\mathrm{u}}$ on $\bar{u}_{x}$ and $t$.

Figures 4 and 5 show that the dimensionless displacement $\bar{u}_{x}$ and dimensionless thickness $t$ decrease with increases of the dimensionless cohesion $\bar{c}_{\mathrm{f}}$ and the internal friction angle $\varphi_{\mathrm{f}}$ of the frozen soil. As shown in Figures 6 and 7, $t$ decreases with increases in the cohesion strength $\bar{c}_{\mathrm{u}}$ and internal friction angle $\varphi_{\mathrm{u}}$ of unfrozen soil, while $\bar{u}_{x}$ increases. In Figure $8, \bar{u}_{x}$ decreases with the increase of dimensionless elastic modulus $\bar{E}_{\mathrm{u}}$ of unfrozen soil. The slight increase of $t$ is mainly due to the deformation of the frozen wall, whose location is very close prior to and after deformation. The calculation results obtained by the new formula exactly match those calculated from large deformation numerical calculations and are inconsistent with the finite-element results of small deformation theory, which means that the

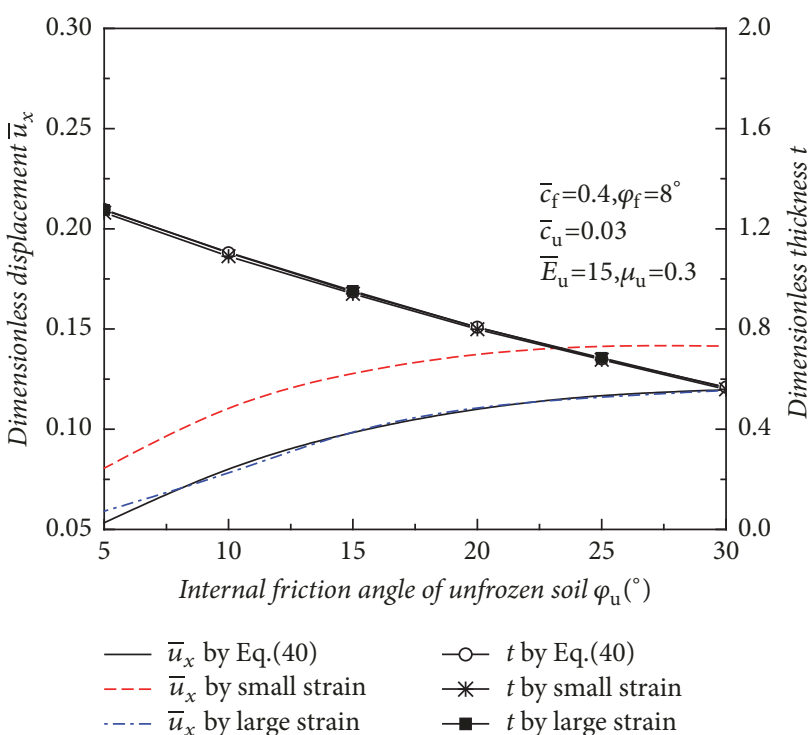

Figure 7: Influence of $\varphi_{\mathrm{u}}$ on $\bar{u}_{x}$ and $t$.

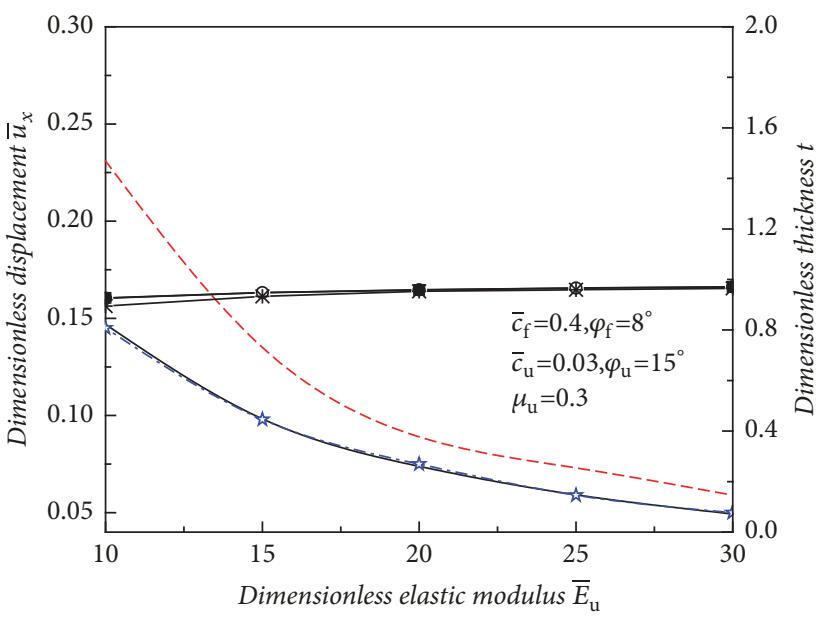

$\begin{array}{ll}-\bar{u}_{x} \text { by Eq. }(40) & -0 t \text { by Eq. }(40) \\ ---\bar{u}_{x} \text { by small strain } & * t \text { by small strain } \\ -\downarrow-\bar{u}_{x} \text { by large strain } & -\quad t \text { by large strain }\end{array}$

FIgURE 8: Influence of $\bar{E}_{\mathrm{u}}$ on $\bar{u}_{x}$ and $t$.

new formula (40) is correct and accurate within 0.2 of large strain.

\section{Case Study}

The following engineering example is presented: a shaft passes through a thick clay layer, and the average temperature of its frozen wall is $-20^{\circ} \mathrm{C}$. The elastic modulus, Poisson's ratio, internal friction angle, and cohesive strength of unfrozen soil are $E_{\mathrm{u}}=100 \mathrm{MPa}, \mu_{\mathrm{u}}=0.3, \varphi_{\mathrm{u}}=15^{\circ}$, and $c_{\mathrm{u}}$ $=0.3 \mathrm{MPa}$, respectively. The aforementioned parameters of frozen soil separately are $E_{\mathrm{f}}=400 \mathrm{MPa}, \mu_{\mathrm{f}}=0.2, \varphi_{\mathrm{f}}=8^{\circ}$, and $c_{\mathrm{f}}=4.0 \mathrm{MPa}$, and its uniaxial compressive strength is $\sigma_{\mathrm{f}}=$ 8.0 $\mathrm{MPa}$. Based on a frozen wall internal radius of $r_{1}^{\prime}=5 \mathrm{~m}$ 
TABLE 1: Comparisons of different design theories.

\begin{tabular}{|c|c|c|c|c|c|}
\hline \multirow{2}{*}{$h / \mathrm{m}$} & \multicolumn{3}{|c|}{ Thickness (m) } & \multirow{2}{*}{$u_{0} / \mathrm{m}$} & \multirow{2}{*}{$w_{1} / \%$} \\
\hline & Liberman & Yang & This paper & & \\
\hline 500 & 6.27 & 2.893 & 2.779 & 0.319 & 13.3 \\
\hline 550 & 7.22 & 3.255 & 3.110 & 0.379 & 15.8 \\
\hline 600 & 8.26 & 3.628 & 3.448 & 0.447 & 18.7 \\
\hline 650 & 9.38 & 4.013 & 3.790 & 0.523 & 22.0 \\
\hline 700 & 10.59 & 4.408 & 4.138 & 0.609 & 25.7 \\
\hline 750 & 11.91 & 4.816 & 4.491 & 0.705 & 29.8 \\
\hline 800 & 13.35 & 5.235 & 4.849 & 0.812 & 34.5 \\
\hline
\end{tabular}

TABLE 2: Inner and outer radii of frozen wall obtained by different calculation methods.

\begin{tabular}{|c|c|c|c|c|c|c|}
\hline \multirow{2}{*}{$h / \mathrm{m}$} & \multicolumn{3}{|c|}{$r_{1} / \mathrm{m}$} & \multicolumn{3}{|c|}{$r_{2} / \mathrm{m}$} \\
\hline & (40) & SS & LS & (40) & SS & LS \\
\hline 500 & 5.322 & 5.395 & 5.312 & 8.101 & 8.151 & 8.101 \\
\hline 550 & 5.381 & 5.486 & 5.371 & 8.492 & 8.559 & 8.492 \\
\hline 600 & 5.448 & 5.598 & 5.438 & 8.895 & 8.991 & 8.894 \\
\hline 650 & 5.522 & 5.736 & 5.512 & 9.312 & 9.446 & 9.310 \\
\hline 700 & 5.605 & 5.892 & 5.596 & 9.743 & 9.919 & 9.742 \\
\hline 750 & 5.697 & 6.074 & 5.687 & 10.188 & 10.413 & 10.186 \\
\hline 800 & 5.798 & 6.281 & 5.798 & 10.647 & 10.947 & 10.644 \\
\hline
\end{tabular}

after deformation (the desired clearance radius), the authors can determine the excavation radius, frozen wall thickness, and the underestimated percentage of excavation volume at a depth range of $500 \sim 800 \mathrm{~m}$.

The initial horizontal ground pressure [27] (expressed in the unit $\mathrm{MPa}$ ) is

$$
p_{0}=0.013 \cdot h,
$$

where $h$ is the depth in meters.

Next, according to (33) (35) and (40) (44), the authors determined the effective thickness of the frozen wall prior to excavation, the excavation radius, and the underestimated percentage of excavation volume (see Tables 1 and 2 and Figures 9-11). The results are as follows.

(1) The results of new design theory are different from those of Liberman's design theory (see Table 1 and Figure 9) because of the poor applicability of Liberman's theory in an ultradeep soil layer. In contrast with Yang's design theory, the new design theory considers the effect of the frozen wall deformation on its thickness. Figure 10 shows that the inner-edge strains of frozen wall (more than 5\%) are large in Yang's design theory, and inner-edge deformation even increases with depth. In actual engineering, the inner-edge deformations must be excavated again to obtain the desired clearance of the shaft, which reduces the effective thickness of the frozen wall and makes the conditions unsafe.

(2) The frozen wall thickness exhibits a nonlinear increase with depth. Moreover, the difference between the new design theory and Yang's design theory increases with depth, and the maximum difference is $38.6 \mathrm{~cm}$.

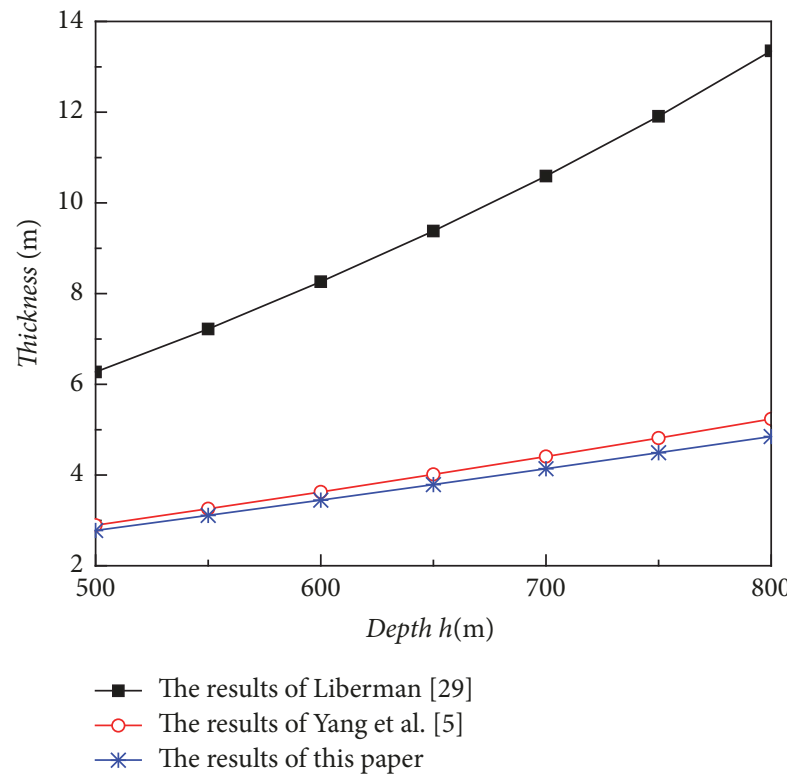

Figure 9: Comparisons of different design theories.

(3) From Table 2 and Figure 11, both the excavation radii and outer radii exhibit nonlinear increase with depth. The calculation results of inner and outer radii of frozen wall obtained by the new formula present considerable deviations from the small deformation calculation results but exactly match those calculated from large deformation numerical calculations (maximum gap is no more than $0.2 \%$ ). Evidently, 


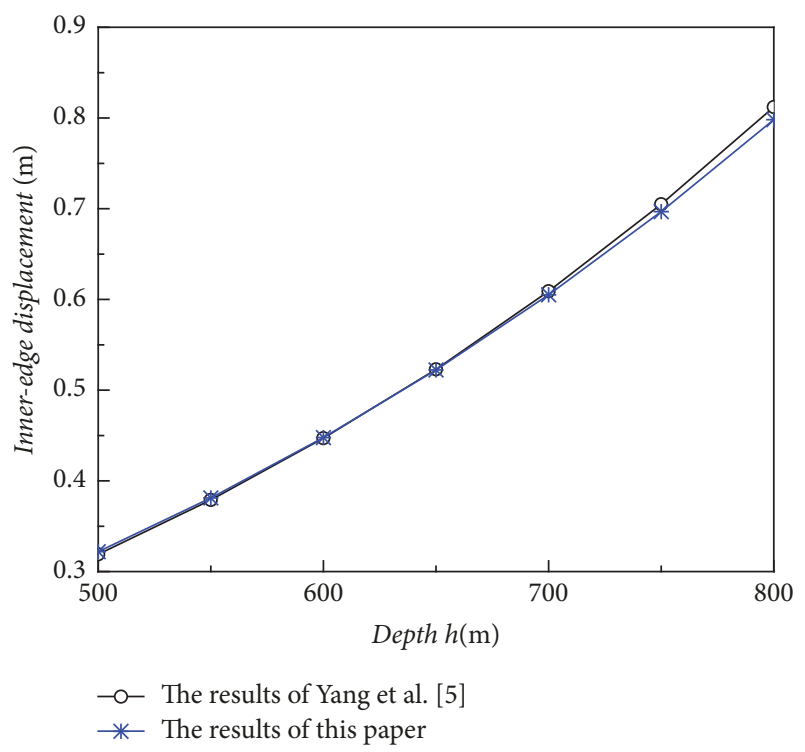

Figure 10: Inner-edge deformation of frozen wall calculated by different theories.

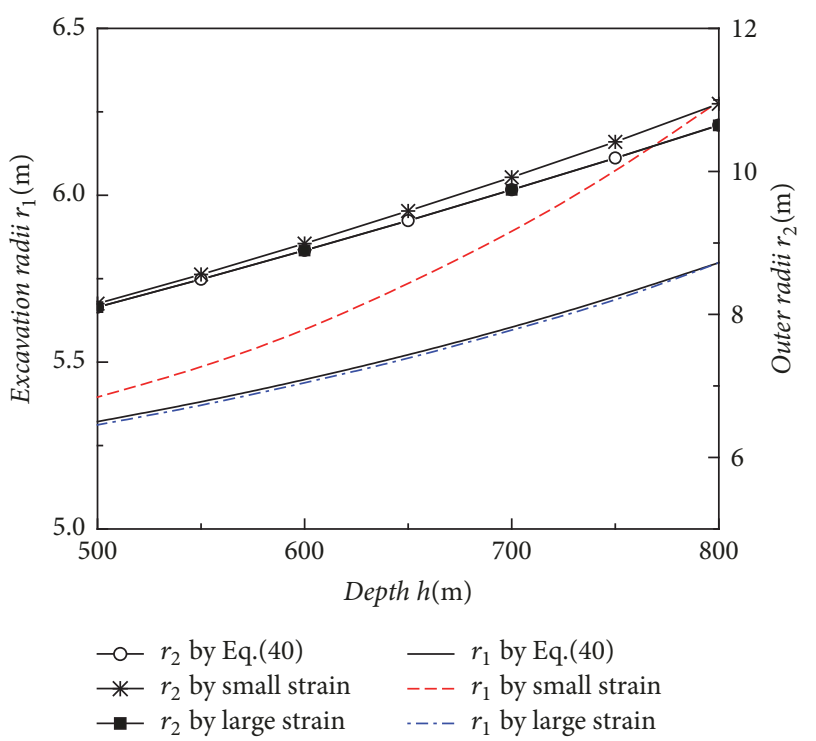

FIGURE 11: Inner and outer radii of frozen wall obtained by different methods.

in the depth of 500 800 m, the frozen wall thickness calculated by previous plastic design theories neglecting sidewall displacement of shaft should be treated cautiously.

(4) The underestimated percentage of excavation volume is between $10 \%$ and $35 \%$. Larger calculation depths correspond to larger underestimated percentages.

$u_{0}$ represents the inner-edge displacement of frozen wall by Yang's theory, SS is the results of small strain finite-element calculation, and LS expresses the large deformation finiteelement calculation results.

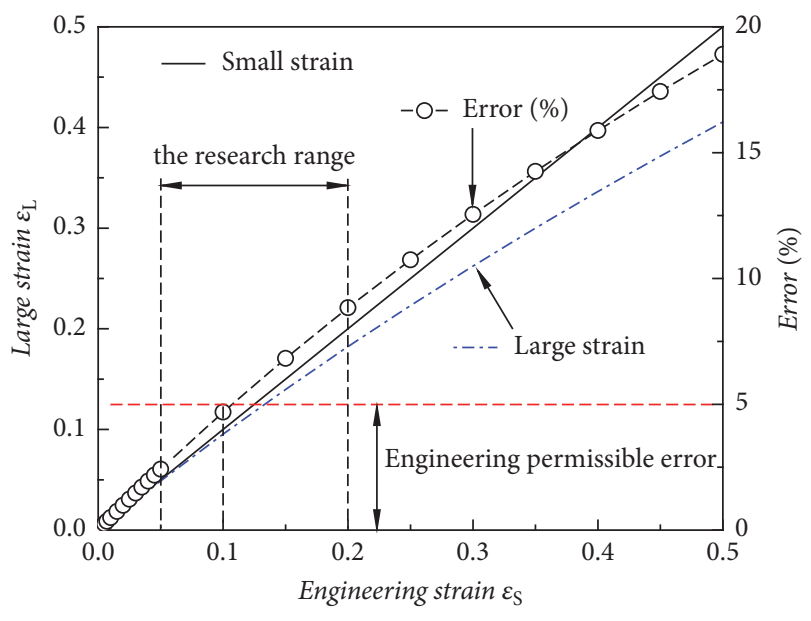

FIGURE 12: Comparisons of large and small strains.

\section{Discussion}

The expressions of engineering strain $\varepsilon_{\mathrm{S}}$ (small strain) and logarithmic strain $\varepsilon_{\mathrm{L}}$ (large strain) are as follows:

$$
\begin{aligned}
& \varepsilon_{\mathrm{S}}=\frac{\Delta l}{l}, \\
& \varepsilon_{\mathrm{L}}=\ln \left(1+\frac{\Delta l}{l}\right)=\ln \left(1+\varepsilon_{\mathrm{S}}\right),
\end{aligned}
$$

where $\Delta l$ represents the deformations of $l$ which is an undeformed length. For any $\varepsilon_{\mathrm{S}}>-1$, the inequality $\varepsilon_{\mathrm{S}} \geq \varepsilon_{\mathrm{L}}$ is valid. Formula (46) can be extended to the power series; then the expression, in the convergence domain $(-1,1]$, can be expressed as

$$
\varepsilon_{\mathrm{L}}=\varepsilon_{\mathrm{S}}-\frac{\varepsilon_{\mathrm{S}}^{2}}{2}+\frac{\varepsilon_{\mathrm{S}}^{3}}{3}-\frac{\varepsilon_{\mathrm{S}}^{4}}{4}+\ldots=\sum_{n=1}^{+\infty}(-1)^{n+1} \frac{\varepsilon_{\mathrm{S}}^{n}}{n} .
$$

Apparently, (47) is also valid for any $\varepsilon_{S} \in[0,0.5]$, and a large strain equals a small strain if the higher-order terms on the right side of (47) are neglected; otherwise, the values of engineering strain are higher than those of the logarithmic strain.

From an engineering point of view, small strain solutions remain sufficient, as long as the error does not exceed $5 \%$ (implying that strains do not exceed 0.1 [7]). As seen in Figure 12, in the range of engineering allowable error, using small-strain solutions instead of large-strain solutions is accurate enough. However, small-strain solutions cause higher errors when an engineering strain range is of 0.1 0.2. And a problem on designing a frozen wall thickness and excavation radii is discussed, in this paper, whose engineeringstrain range is of $0.05 \sim 0.2$. Therefore, for the plastic design of a frozen wall thickness and excavation radii in an ultradeep layer, the large-strain formula is more reasonable than the small-strain formula. 


\section{Conclusions}

This paper described a new design theory for frozen wall thickness which considers the characteristics of large deformation. The influences of crustal stress, cohesion and internal friction angle of frozen wall, cohesion and internal friction angle, and elastic modulus of unfrozen soil on the effective thickness of frozen wall and the excavation radius were analyzed. The conclusions are as follows.

(1) In the design of a frozen wall in an ultradeep soil layer, the impact of large deformation should be considered. At greater depths, the impact of large deformation is more apparent.

(2) The new design theory of frozen wall thickness proposed in this paper appropriates to large deformation frozen wall within a strain of 0.2 . The theory can provide safer and more reasonable theoretical support for the design of a frozen wall in an ultradeep soil layer.

(3) The new formulas can accurately calculate the volume of earthwork excavation. The example presented herein showed that calculated frozen wall thickness based on prior theories will result in an underestimated excavation volume by approximately $10-35 \%$, with the underestimated volume increasing with depth.

\section{Conflicts of Interest}

The authors declare that there are no conflicts of interest regarding the publication of this paper.

\section{Acknowledgments}

This work was supported by the National Key Research and Development Program of China (Grant no. 2016YFC0600904) and the National Natural Science Foundation of China (Grant no. 41472224).

\section{References}

[1] O. B. Andersland and B. Ladanyi, Frozen Ground Engineering, John Wiley \& Sons, Hoboken, NJ, USA, 2004.

[2] R. S. Yang, Q. X. Wang, and L. Y. Yang, "A closed-form elastic solution for irregular frozen wall of inclined shaft considering the interaction with ground," International Journal of Rock Mechanics and Mining Sciences, vol. 100, pp. 62-72, 2017.

[3] W. H. Yang, "Development and prospect of freezing shaft sinking technology in China over the past decade," in High-Level Academic Forum for the 50th Anniversary of China Coal Society, China Coal Society, 2012.

[4] W.-H. Yang, Z.-J. Yang, and D.-L. Bo, "Elastic-plastic design theory of frozen soil wall based on interaction between frozen wall and surrounding rock," Chinese Journal of Geotechnical Engineering, vol. 35, no. 1, pp. 175-180, 2013.

[5] W.-H. Yang, Z.-B. Du, Z.-J. Yang, and D.-L. Bo, "Plastic design theory of frozen soil wall based on interaction between frozen soil wall and surrounding rock," Chinese Journal of Geotechnical Engineering, vol. 35, no. 10, pp. 1857-1862, 2013.

[6] A. Vrakas and G. Anagnostou, "A finite strain closed-form solution for the elastoplastic ground response curve in tunnelling,"
International Journal for Numerical and Analytical Methods in Geomechanics, vol. 38, no. 11, pp. 1131-1148, 2014.

[7] A. Vrakas and G. Anagnosto, "A simple equation for obtaining finite strain solutions from small strain analyses of tunnels with very large convergences," Géotechnique, vol. 65, no. 11, pp. 936944, 2015.

[8] J. P. Carter, J. R. Booker, and S. K. Yeung, "Cavity expansion in cohesive frictional soils," Géotechnique, vol. 36, no. 3, pp. 349$358,1986$.

[9] E. Detournay, "Elastoplastic model of a deep tunnel for a rock with variable dilatancy," Rock Mechanics and Rock Engineering, vol. 19, no. 2, pp. 99-108, 1986.

[10] H. S. Yu and G. T. Houlsby, "Finite cavity expansion in dilatant soils: loading analysis," Géotechnique, vol. 41, no. 2, pp. 173-183, 1991.

[11] H. S. Yu and R. K. Rowe, "Plasticity solutions for soil behaviour around contracting cavities and tunnels," International Journal for Numerical and Analytical Methods in Geomechanics, vol. 23, no. 12, pp. 1245-1279, 1999.

[12] L. F. Cao, C. I. Teh, and M. F. Chang, "Undrained cavity expansion in modified Cam clay I: theoretical analysis," Géotechnique, vol. 51, no. 4, pp. 323-334, 2001.

[13] H. S. Yu and J. P. Carter, "Rigorous similarity solutions for cavity expansion in cohesive-frictional soils," International Journal of Geomechanics, vol. 2, no. 2, pp. 233-258, 2002.

[14] J. D. Zhao and G. Wang, "Unloading and reverse yielding of a finite cavity in a bounded cohesive-frictional medium," Computers \& Geosciences, vol. 37, no. 1-2, pp. 239-245, 2010.

[15] S. L. Chen and Y. N. Abousleiman, "Exact undrained elastoplastic solution for cylindrical cavity expansion in modified cam clay soil," Géotechnique, vol. 62, no. 5, pp. 447-456, 2012.

[16] T. Cohen and D. Durban, "Fundamental solutions of cavitation in porous solids: a comparative study," Acta Mechanica, vol. 224, no. 8, pp. 1695-1707, 2013.

[17] A. Vrakas and G. Anagnostou, "Finite strain elastoplastic solutions for the undrained ground response curve in tunnelling," International Journal for Numerical and Analytical Methods in Geomechanics, vol. 39, no. 7, pp. 738-761, 2015.

[18] H. S. Yu, Cavity Expansion Methods in Geomechanics, Springer, Dordrecht, the Netherlands, 2000.

[19] P. Papanastasiou and D. Durban, "Elastoplastic analysis of cylindrical cavity problems in geomaterials," International Journal for Numerical and Analytical Methods in Geomechanics, vol. 21, no. 2, pp. 133-149, 1997.

[20] D. Durban and P. Papanastasiou, "Elastoplastic response of pressure sensitive solids," International Journal for Numerical and Analytical Methods in Geomechanics, vol. 21, no. 7, pp. 423441, 1997.

[21] D. Durban and P. Papanastasiou, "Cylindrical cavity expansion and contraction in pressure sensitive geomaterials," Acta Mechanica, vol. 122, no. 1-4, pp. 99-122, 1997.

[22] D. Durban and N. A. Fleck, "Spherical cavity expansion in a drucker-prager solid," Journal of Applied Mechanics, vol. 64, no. 4, pp. 743-750, 1997.

[23] D. Durban and R. Masri, "Dynamic spherical cavity expansion in a pressure sensitive elastoplastic medium," International Journal of Solids and Structures, vol. 41, no. 20, pp. 5697-5716, 2004.

[24] P. Chadwick, "The quasi-static expansion of a spherical cavity in metals and ideal soils," The Quarterly Journal of Mechanics and Applied Mathematics, vol. 12, pp. 52-71, 1959. 
[25] W.-H. Yang, Z.-J. Yang, T. Han, C. Zhang, and D.-L. Bo, "Elastic design theory of frozen soil wall based on interaction between frozen soil wall and surrounding rock," Chinese Journal of Geotechnical Engineering, vol. 34, no. 3, pp. 516-519, 2012.

[26] Y. M. Lai, H. Wu, Z. W. Wu, S. Liu, and X. Den, "Analytical viscoelastic solution for frost force in cold-region tunnels," Cold Regions Science and Technology, vol. 31, no. 3, pp. 227-234, 2000.

[27] J. J. Weng, Special Construction Engineering of Mine Shaft and Drift, Coal Industry Press, Beijing, China, 1991.

[28] D. Wang, B. Bienen, M. Nazem et al., "Large deformation finite element analyses in geotechnical engineering," Computers \& Geosciences, vol. 65, pp. 104-114, 2015.

[29] Y. S. Kim, J.-M. Kang, J. Lee, S.-S. Hong, and K.-J. Kim, “Finite element modeling and analysis for artificial ground freezing in egress shafts," KSCE Journal of Civil Engineering, vol. 16, no. 6, pp. 925-932, 2012.

[30] G. Wachsmuth, M. Lätzer, and E. Leidich, "Analytical computation of multiple interference fits under elasto-plastic deformations," Zamm Journal of Applied Mathematics \& Mechanics, vol. 94, no. 12, pp. 1058-1064, 2014. 


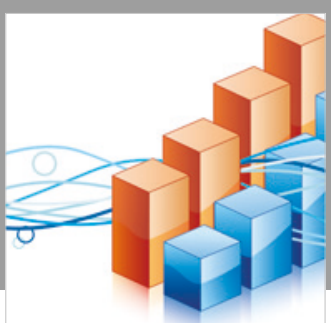

Advances in

Operations Research

\section{-n-m}
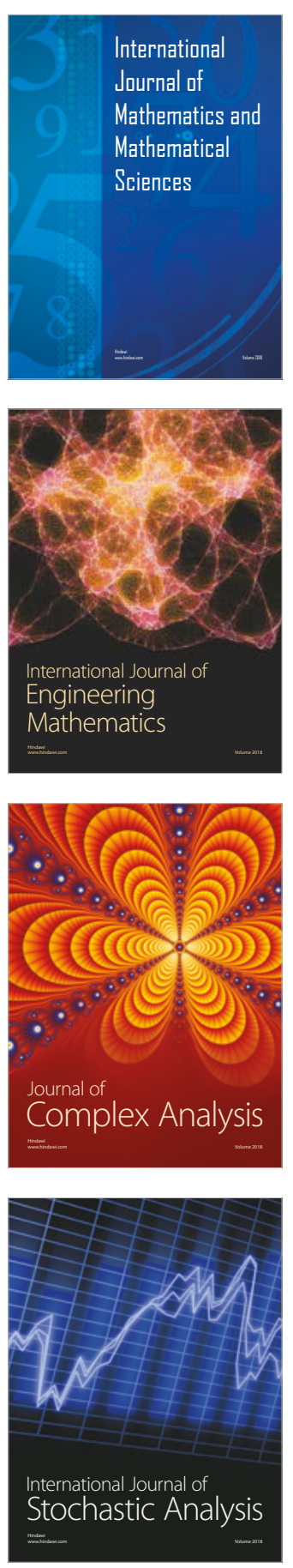
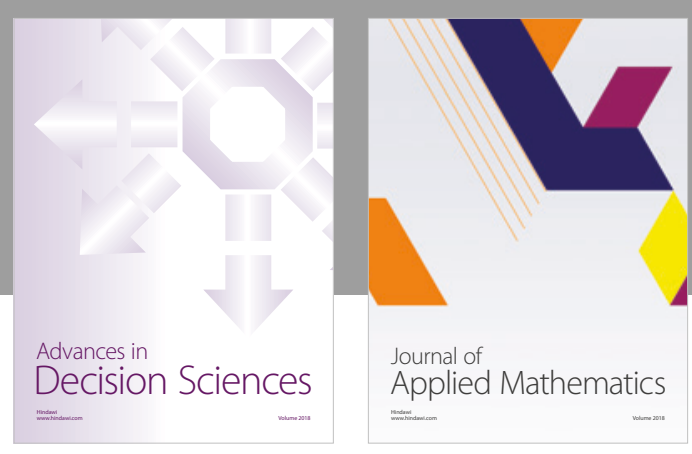

Journal of

Applied Mathematics
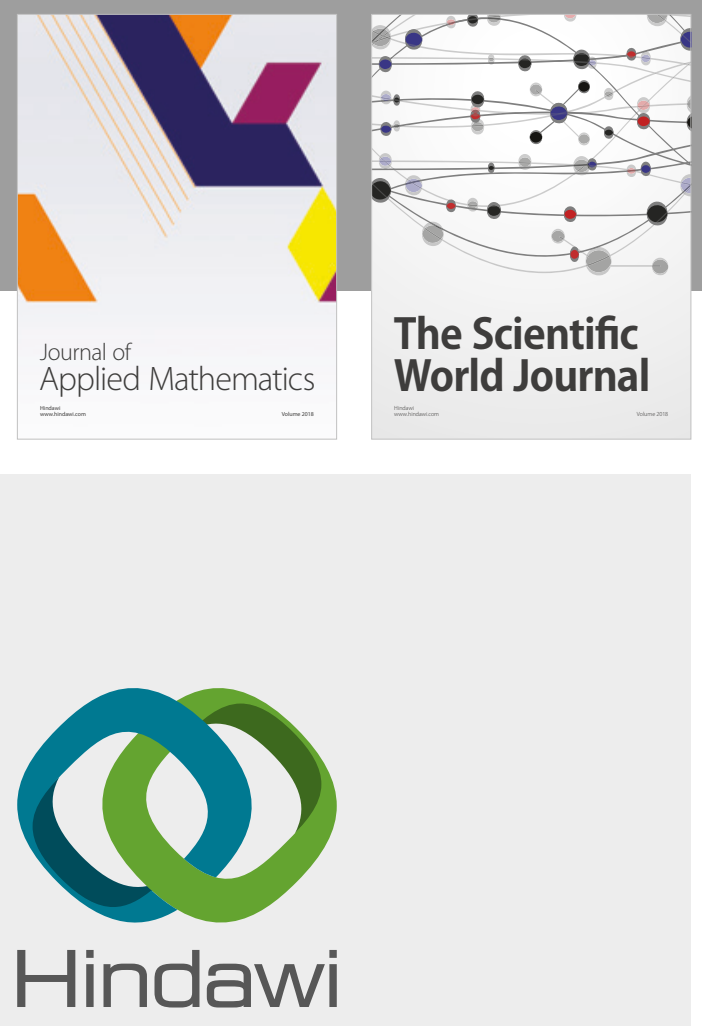

Submit your manuscripts at

www.hindawi.com

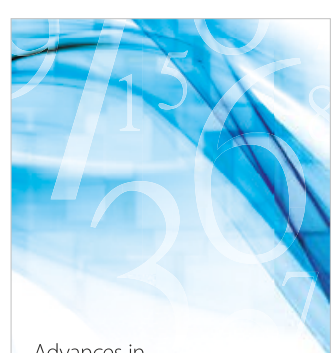

Advances in
Numerical Analysis
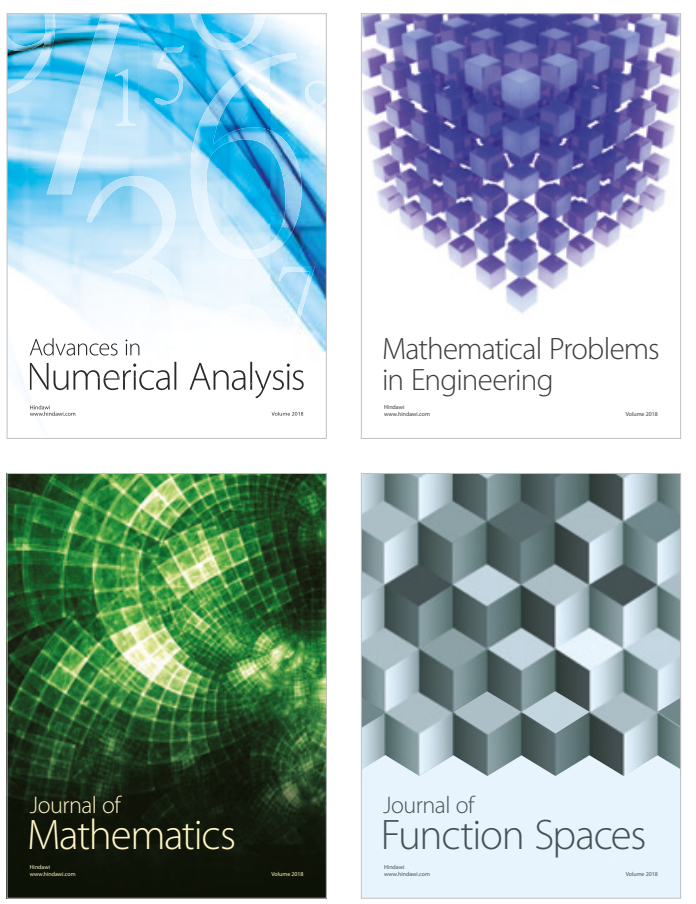

Mathematical Problems in Engineering

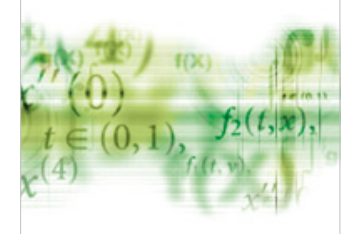

International Journal of

Differential Equations

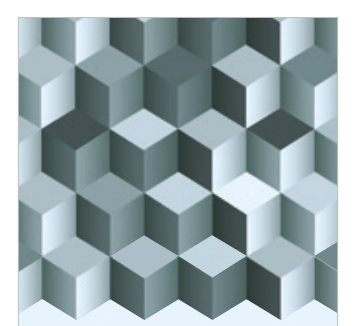

Journal of

Function Spaces

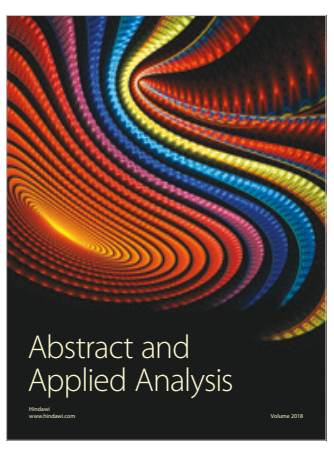

The Scientific

World Journal

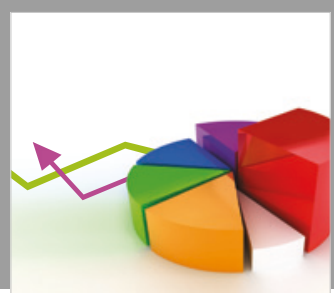

Journal of

Probability and Statistics
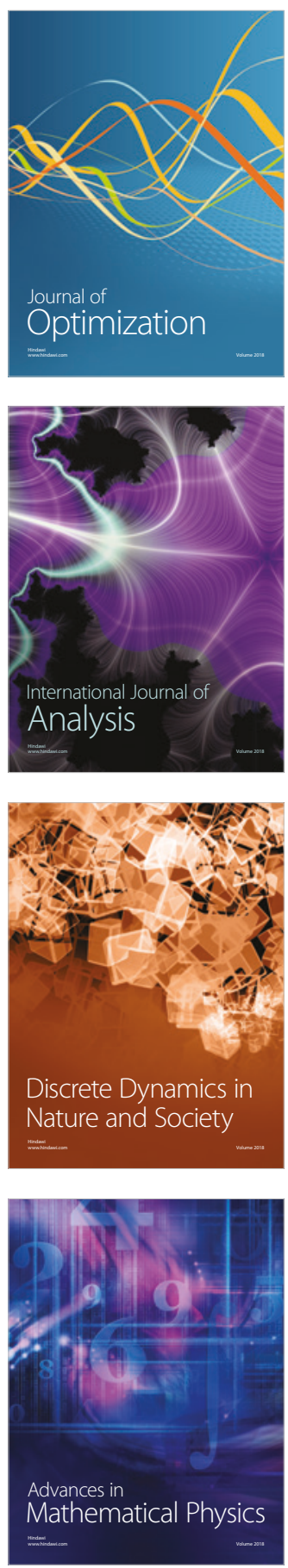